NBER WORKING PAPER SERIES

\title{
IS IT IS OR IS IT AIN'T MY OBLIGATION? REGIONAL DEBT IN A FISCAL FEDERATION
}

\author{
Russell Cooper \\ Hubert Kempf \\ Dan Peled \\ Working Paper 11655 \\ http://www.nber.org/papers/w11655 \\ NATIONAL BUREAU OF ECONOMIC RESEARCH \\ 1050 Massachusetts Avenue \\ Cambridge, MA 02138 \\ September 2005
}

This is a revised version of our NBER Working Paper \#10239. We are grateful to the CNRS and the NSF for financial support and to the late Louis Jordan from whom we freely borrowed the title. Cooper thanks the Research Department at the Federal Reserve Bank of Minneapolis for its support. Helpful comments and questions from Maria Alzua, Marco Bassetto, Micha Ben-Gad, Eddie Dekel, Patrick Kehoe, Todd Keister, Robert E. Lucas, John Shea, and Yoram Weiss, as well as seminar participants at the Federal Reserve Bank of Dallas, the Bank of Israel, the European Central Bank, SED Paris 2003, T2M Orleans 2004,PET Peking 2004, the University of Maryland, Tel Aviv University, the University of Haifa, the Anglo-French seminar in macroeconomics, the European University Institute, the University of Pavia and the University of Bologna are very much appreciated. The views expressed herein are those of the author(s) and do not necessarily reflect the views of the National Bureau of Economic Research.

(C2005 by Russell Cooper, Hubert Kempf and Dan Peled. All rights reserved. Short sections of text, not to exceed two paragraphs, may be quoted without explicit permission provided that full credit, including (C) notice, is given to the source. 
Is It Is or Is It Ain't My Obligation? Regional Debt in a Fiscal Federation

Russell Cooper, Hubert Kempf and Dan Peled

NBER Working Paper No. 11655

September 2005

JEL No. E6, F4, R5

\title{
$\underline{\text { ABSTRACT }}$
}

This paper studies the repayment of regional debt in a multi-region economy with a central authority: who pays the obligation issued by a region? With commitment, a central government will use its taxation power to smooth distortionary taxes across regions. Absent commitment, the central government may be induced to bailout the regional government in order to smooth consumption and distortionary taxes across the regions. We characterize the conditions under which bailouts occur and their welfare implications. The gains to creating a federation are higher when the (government spending) shocks across regions are negatively correlated and volatile. We use these insights to comment on actual fiscal relations in three quite different federations: the US, the European Union and Argentina.

\author{
Russell Cooper \\ Department of Economics \\ University of Texas \\ Austin, TX 78712 \\ and NBER \\ cooper@eco.utexas.edu \\ Hubert Kempf \\ EUREQua, Universite \\ Paris-1 Pantheon-Sorbonne \\ 106 Boulevard de l'Hopital \\ F-75013 Paris \\ FRANCE \\ hubert.kempf@univ-paris1.fr \\ Dan Peled \\ Department of Economics \\ University of Haifa \\ Haifa 31905 \\ ISRAEL \\ dpeled@econ.haifa.il
}




\title{
Is it is or is it Ain't my Obligation? Regional Debt in a Fiscal Federation *
}

\author{
Russell Cooper ${ }^{\dagger}$ Hubert Kempf $;$ and Dan Peled ${ }^{\S}$
}

September 5, 2005

\begin{abstract}
This paper studies the repayment of regional debt in a multi-region economy with a central authority: who pays the obligation issued by a region? With commitment, a central government will use its taxation power to smooth distortionary taxes across regions. Absent commitment, the central government may be induced to bailout the regional government in order to smooth consumption and distortionary taxes across the regions. We characterize the conditions under which bailouts occur and their welfare implications. The gains to creating a federation are higher when the (government spending) shocks across regions are negatively correlated and volatile. We use these insights to comment on actual fiscal relations in three quite different federations: the US, the European Union and Argentina.
\end{abstract}

\section{Introduction}

Fiscal constraints, typically in the form of debt limits, on governments within a federation are prevalent. Restrictions on borrowing by states in the U.S. and the Stability and Growth Pact of the European Monetary Union are leading examples. These fiscal constraints have an obvious cost: they limit the ability of a regional government to smooth distortionary taxes over time. These constraints have a more subtle gain: they may

*This is a revised version of our NBER Working Paper \#10239. We are grateful to the CNRS and the NSF for financial support and to the late Louis Jordan from whom we freely borrowed the title. Cooper thanks the Research Department at the Federal Reserve Bank of Minneapolis for its support. Helpful comments and questions from Maria Alzua, Marco Bassetto, Micha Ben-Gad, Eddie Dekel, Patrick Kehoe, Todd Keister, Robert E. Lucas, John Shea, and Yoram Weiss, as well as seminar participants at the Federal Reserve Bank of Dallas, the Bank of Israel, the European Central Bank, SED Paris 2003, T2M Orleans 2004,PET Peking 2004, the University of Maryland, Tel Aviv University, the University of Haifa, the Anglo-French seminar in macroeconomics, the European University Institute, the University of Pavia and the University of Bologna are very much appreciated.

${ }^{\dagger}$ Department of Economics, University of Texas, Austin, TX. 78712, cooper@eco.utexas.edu

${ }^{\ddagger}$ EUREQua, Université Paris-1 Panthéon-Sorbonne, 106 Boulevard de l’Hopital, F-75013 Paris, France, kempf@univ-paris1.fr

$\S$ Department of Economics, University of Haifa, Haifa 31905, Israel, dpeled@econ.haifa.ac.il 
substitute for the inability of a central government to commit not to bailout a regional government. ${ }^{1}$ In anticipation of a bail-out, regional governments will run excessive deficits in an attempt to spread the costs of local public goods onto agents in other regions. The resulting inefficiency is a consequence of the commitment problem of the central government. If the central government could commit not to bailout a regional government, excessive deficits would not arise. Thus we ask: what is the source of the commitment problem and what remedies are there to overcome it?

We highlight two motivations for an ex post bail-out of regional debt by the central government and thus two sources of the commitment problem. First, a central government may bailout the debt of regional government in order to smooth consumption across agents. This consumption smoothing motive reflects the objective of a central government which values equality of consumption across agents in the economy. In the model, the objective function of a central government is to maximize the sum of the welfare of agents in the multiple regions. If the utility functions of the agents are strictly concave, then the objective function of the central government will inherit this property and thus a desire to smooth consumption. Without commitment, the central government can be induced to bailout a regional government if the resulting allocation is more equitable.

The extent of the consumption smoothing motive will depend on the allocation of debt holdings across agents. While individual agents will be, in equilibrium, indifferent regarding the composition of their portfolio, bailout will occur when a sufficiently large fraction of the debt of a rich region is held by agents in a poorer region. If, instead, debt issued by a region is held solely by agents within that region, then there is no bailout and each region repays its own obligation with regional taxes.

Second, the central government may have an incentive to smooth distortionary taxes and thus bailout the debt of a regional government. This tax smoothing motive reflects the presence of distortionary labor taxes. The central government has, by assumption, the power to tax all agents at the same rate and thus to smooth the tax burden across agents in different regions. Thus if two regions have different tax burdens, the central government will be induced to use its tax power to smooth distortionary taxes across them. This tax smoothing motive does not rest on the distribution of debt holdings across regions.

Independent of the source of the commitment problem, the bail-out is ex post in the interest of the central government and thus the agents in the economy it represents. However, from an ex ante perspective, the central government would, if feasible, commit to other policies. ${ }^{2}$ Thus, private agents in the economy are worse off because of the central government's inability to commit not to bailout the regional governments. In equilibrium, the bail-out limits consumption and tax smoothing in the overall economy.

Even absent commitment, there may still be gains to a federation. These economic gains depend positively

\footnotetext{
${ }^{1}$ Commitment problems also lie at the heart of other analyzes of interactions between levels of governments, including Zarazaga (1995), Chari and Kehoe (1998), Cooper and Kempf (2001), Cooper and Kempf (2004) and Sanguinetti and Tommasi (2004).

${ }^{2}$ As we shall see, in some cases these policies include some ex ante intervention to smooth taxes across regions. Thus as the analysis proceeds we are careful to distinguish these flows from the ex post transfers which we associate with a bail-out.
} 
on the volatility of the spending shocks, and negatively on their correlation. When spending shocks are sufficiently volatile and negatively correlated across regions, revenue sharing across regions induced by a bail-out is an efficient way to minimize the variability of distortionary taxes in each region.

The striking result that a central government will bailout regional governments raises the question of limiting bail-outs and motivates various fiscal restrictions within federations. Institutional features like balanced-budget constitutional provisions are common in many federal unions, as in the U.S. These same issues reappear in the ongoing discussion of fiscal constraints within the European Union. We use our model to comment on these devices.

\section{A two region economy}

We study allocations in an economy comprised of two regions. At one extreme, each region may be characterized by its own government, fully sovereign and able to tax its citizens. It finances its public programs by taxation and receives no transfers from any other authority. Alternatively, there may exist an integrated government, covering the entire economy, able to finance regional public programs by means of a tax policy levied on all agents irrespective of the region where they live. These two institutional settings provide benchmark allocations.

\subsection{Model Overview}

A two-period economy allows us to focus on consumption and tax smoothing in a dynamic setting. The economy is composed of two regions, $i=1,2$. In each period of life, agents supply labor, $n_{t}^{i}$, and consume (net of the disutility of work), $c_{t}^{i}$, for $t=1,2$ and $i=1,2 .{ }^{3}$ Each unit of labor input produces 1 unit of the single good. After tax, this output can be either consumed or stored. We assume that agents have access to a storage technology with an exogenous return of $R$. Importantly, there is no individual mobility: agents live in one region and cannot avoid being taxed by their local government.

Thus we consider the following optimization problem for a representative agent in one of the regions:

$$
\max _{\left\{n_{1}, n_{2}, s\right\}} u\left(G+e+n_{1}\left(1-\tau_{1}\right)-\frac{n_{1}^{1+\gamma}}{1+\gamma}-s\right)+\beta v\left(n_{2}\left(1-\tau_{2}\right)-\frac{n_{2}^{1+\gamma}}{1+\gamma}+s R\right)
$$

where $u(\cdot)$ and $v(\cdot)$ are strictly increasing and concave. ${ }^{4}$ In what follows, we sometimes assume that $v\left(c_{2}\right)=$ $c_{2}$. This is an important restriction as it allows us to focus on bail-outs associated with the sharing of distortionary taxes rather than bail-outs associated with redistribution of consumption alone. Agents incur a disutility of work, in consumption terms, given by $\frac{n^{1+\gamma}}{1+\gamma}$ where $\gamma>0$.

Public spending per capita, $G$, enters directly into utility as a perfect substitute for private consumption. In the subsequent analysis, $G$ will be taken as a random variable with a known distribution. The optimization

\footnotetext{
${ }^{3}$ The notation has subscripts to denote the time period and superscripts to denote the region. Variables without superscripts are aggregates.

${ }^{4}$ Since we are looking at a single region, the superscript is suppressed.
} 
problem is stated here for a given realization of $G$. There is a first period endowment of $e$ which creates an incentive to save, denoted by $s$. The tax rate on labor income in period $t$ is given by $\tau_{t}$ so labor income, after taxes, is $n_{t}\left(1-\tau_{t}\right)$ in period $t$.

The first-order condition for labor in any period is

$$
(1-\tau)^{\frac{1}{\gamma}}=n
$$

where $\tau$ is the tax rate prevailing in that period. Call this labor supply relationship $n(\tau)$. Let $\xi(\tau)$ be the elasticity of labor supply with respect to the labor tax: $\xi(\tau)=\frac{-\tau}{\gamma(1-\tau)}$. From (2), while the elasticity of labor supply would be constant with respect to $(1-\tau)$, it is not a constant with respect to $\tau$.

Let the after-tax total contribution to consumption from work, net of the disutility of work, be

$$
Z(\tau) \equiv n(\tau)(1-\tau)-\frac{n(\tau)^{1+\gamma}}{1+\gamma} .
$$

Note $Z^{\prime}(\tau)=-n(\tau)$, when $n(\tau)$ satisfies (2).

Using $Z(\cdot)$, the household optimization problem can be recast as

$$
W\left(\tau_{1}, \tau_{2} \mid G\right)=\max _{s} u\left(G+e+Z\left(\tau_{1}\right)-s\right)+\beta v\left(Z\left(\tau_{2}\right)+s R\right) .
$$

The first-order condition is

$$
u^{\prime}\left(c_{1}\right)=\beta R v^{\prime}\left(c_{2}\right)
$$

From (4)

$$
W_{\tau_{1}}=u^{\prime}\left(c_{1}\right) Z^{\prime}\left(\tau_{1}\right), \quad W_{\tau_{2}}=\beta v^{\prime}\left(c_{2}\right) Z^{\prime}\left(\tau_{2}\right) .
$$

\subsection{Isolated regions}

The multi-region economy to be analyzed in this paper consists of two economies, identical in all respects to the one presented above. The public spending shocks $\left(G^{1}, G^{2}\right)$ are drawn from a joint distribution. The regional spending shocks may be correlated. In fact, some of our results depend on the magnitude and sign of this correlation.

We first assume there is a single government in each region, $i=1,2$, determining its fiscal policy. Each government is isolated, as there is no exchange nor any spillovers across regions.

To find optimal taxes, the representative government in region $i$ will choose $\left(\tau_{1}^{i}, \tau_{2}^{i}\right)$ to maximize $W\left(\tau_{1}^{i}, \tau_{2}^{i} \mid G^{i}\right)$ subject to the present value budget constraint of

$$
G^{i}=\tau_{1}^{i} n\left(\tau_{1}^{i}\right)+\frac{\tau_{2}^{i} n\left(\tau_{2}^{i}\right)}{R}=\left(I\left(\tau_{1}^{i}\right)+\frac{I\left(\tau_{2}^{i}\right)}{R}\right)
$$


where $I(\tau) \equiv \tau n(\tau)$ and $G^{i}$ is given. ${ }^{5}$ The maximal amount of revenue the government can receive in a period is obtained by a tax rate of $\tau=\frac{\gamma}{1+\gamma}$. We assume that $G^{i}$ is bounded above by $I\left(\frac{\gamma}{1+\gamma}\right) \frac{1+R}{R}$ so that (7) can always be satisfied with a constant tax rate.

If period 1 revenues do not cover $G^{i}$, then the regional government issues debt to cover the deficit. In equilibrium, this debt pays the same return $R$ as private storage. The optimal tax policy for the isolated regional government is characterized by

Proposition 1 The optimal tax policy for the isolated region satisfies $\tau_{t}^{i}=\tau^{i A}$ for $t=1,2$. Further, agent's utility and consumption levels are decreasing functions of $G^{i}{ }^{6}$

Here the optimal allocation for the isolated regions is indicated by a superscript $A$ and is referred to as the autarkic equilibrium. The optimal allocation entails both intertemporal tax smoothing and consumption smoothing. The tax smoothing is seen by the equality of income taxes across periods in Proposition 1. The government uses debt to smooth out distortionary taxes over time. Given the optimal tax policy from Proposition 1 along with the budget constraint, the amount of debt issued by the government is $B^{i A}=G^{i}-\tau^{i A} n\left(\tau^{i A}\right)=\frac{\tau^{i A} n\left(\tau^{i A}\right)}{R}$. Agents use access to capital market to smooth consumption, as in (5).

If labor supply was completely inelastic, then of course taxes would not be distortionary, i.e. $\gamma \rightarrow \infty$ so that $n(\tau)=\eta$. In this case, the timing of taxes would not matter for consumption and labor allocations. This is the familiar result of Ricardian equivalence applied to this economy.

Clearly, there is no consumption smoothing across regions in the autarkic equilibrium. Consumption, $\left(c_{1}^{i A}, c_{2}^{i A}\right)$, and taxation, $\tau^{i A}$, depend on $G^{i}$ but not on $G^{-i}$. Variations in the exogenous level of $G^{i}$ influence the lifetime utility of agents directly through the presence of $G^{i}$ in the utility function and also indirectly through the dependence of $\tau^{i A}$ on $G^{i}$.

The second part of the proposition shows that utility and consumption levels fall as $G^{i}$ increases. Evidently the direct effect of $G^{i}$ on utility is more than offset by the taxation effect. To understand this result, if taxes were not distortionary, utility would be independent of $G^{i}$ since, from the government budget constraint, total tax revenues would equal the transfer. But, when labor supply is responsive to tax rates, then increases in $G^{i}$ are welfare reducing due to the distortions of taxes on labor supply.

Let $W^{A}$ be the expected utility of an agent in this economy where the uncertainty is over the realized value of government spending $G$. This level of expected utility will be used to characterize the welfare effects of a federation.

\subsection{An Integrated Federation}

Now suppose that taxation in this two-region economy is determined by a central government $(C G)$. Since there is a single government entity setting tax policies for all groups of agents in all periods, we term this

\footnotetext{
${ }^{5}$ Throughout our analysis, we study the upward sloping branch of the Laffer curve. So if there are multiple levels of $\tau$ such that $I(\tau)=X$, we select the lowest value of $\tau$.

${ }^{6}$ The proofs of the propositions are in the Appendix.
} 
the integrated solution.

Let $\tau_{t}^{i}$ for $i=1,2$ and $t=1,2$ denote the period $t$ tax rate set for region $i$ by the $C G .^{7}$ As before, if the $C G$ elects not to finance $G^{i}$ for $i=1,2$ through period 1 taxes, then it issues debt which pays a return of $R$ to finance the excess of expenditures over tax revenues.

The $C G$ has an objective to maximize the welfare of the agents across the two regions, which we measure as the sum of lifetime expected utilities, using population weights as welfare weights. This could be amended to allow for political pressure different from population to determine $C G$ policy.

Thus the $C G$ chooses a tax policy to solve

$$
\max _{\tau_{t}^{i}} \sum_{i=1,2} \Delta^{i} W\left(\tau_{1}^{i}, \tau_{2}^{i} \mid G^{i}\right)
$$

subject to the government budget constraint of

$$
\sum_{i=1,2} \Delta^{i} G^{i}=\sum_{i=1,2} \Delta^{i} I\left(\tau_{1}^{i}\right)+\frac{1}{R}\left[\sum_{i=1,2} \Delta^{i} I\left(\tau_{2}^{i}\right)\right]
$$

where $\Delta^{i}$ is the share of the population in region $i$.

Proposition 2 The solution to (8)-(9) entails tax smoothing over time by each region: $\tau_{t}^{i}=\tau^{i *}$ for $t=1,2$. Further, if $G^{i}$ increases, then $\tau^{j *}$ increases for $j=1,2$.

The optimal taxes, denoted with a superscript ${ }^{*}$, in periods 1 and 2 are equal. This tax smoothing reflects the gain to the smoothing of distortionary taxes over time within a region. This form of tax smoothing was also present in the solution of the single region's problem. But, through integration, the tax rates may be at different levels.

The second part of the proposition establishes that tax rates in each region depend on the level of government spending in each of the regions. This interaction across regions is a key aspect of our model as it highlights the ex ante optimality of revenue sharing. So, for example, an increase in $G^{1}$ is met by an increase in taxes in both regions 1 and 2. The increase in distortionary taxes needed to finance the increase in region 1 spending is spread across time and across regions. Under autarky, $\tau^{i A}$ is independent of $G^{j}$ and the sharing of the tax burden is not feasible. Put differently, in the integrated solution the difference in tax rates across regions is smaller than under autarky for any $\left(G^{1}, G^{2}\right)$ realization.

Complete tax smoothing across regions, defined as $\tau^{1 *}=\tau^{2 *}$, will occur in two special cases. First, suppose $v(c)=c .^{8}$ In this case, $\tau^{1 *}=\tau^{2 *}$ will satisfy the first-order conditions implying $c_{1}^{1}=c_{1}^{2}$. Differences in $G^{i}$ are reflected in different levels of $s^{i}$ and thus in $c_{2}^{i}$. If $G^{1}>G^{2}$, then $s^{1}>s^{2}$ implying $c_{2}^{1}>c_{2}^{2}$.

Second, suppose that regional public spending is perfectly correlated, $G^{1}=G^{2}$. In this case, the solution with integration will be perfectly symmetric so that tax rates are equal. When the spending levels are

\footnotetext{
${ }^{7}$ Adding in another tax common to all agents would be redundant.

${ }^{8} \mathrm{~A}$ similar argument holds if $u(c)=c$. The case of $v(c)=c$ will be used extensively below.
} 
perfectly correlated, there are no gains to revenue sharing. In fact, given the symmetry across regions, consumption levels will be equalized as well.

As a final special case, assume there are no distortions from taxation: i.e. $\gamma \rightarrow \infty$ so that $n(\tau)=\eta$ and $Z(\tau)=\eta(1-\tau)$. This implies $Z^{\prime}(\tau)=-\eta$ and $I^{\prime}(\tau)=\eta$ so $\frac{Z^{\prime}(\tau)}{I^{\prime}(\tau)}=-1$. Following the first-order conditions contained in the proof, $c_{1}^{1}=c_{1}^{2}$ and $c_{2}^{1}=c_{2}^{2} \cdot{ }^{9}$ Thus when taxes are not distortionary the integrated solution implies consumption smoothing across regions. In fact, this is exactly the same allocation obtained under autarky: the regional tax rate is set to balance the regional budget.

Let $W^{*}$ be the expected value of the $C G$ 's objective in the solution to (8) where the expectation is over the joint distribution of $G^{i}$ for $i=1,2$. As defined earlier, $W^{A}$ is the expected value of the government's problem under autarky.

Proposition 3 Comparing expected utility in autarky with that obtained under integration, (i) $W^{*} \geq W^{A}$, (ii) $W^{*}>W^{A}$ if $G^{1} \neq G^{2}$ and labor taxation is distortionary and (iii) $W^{*}=W^{A}$ if taxes are not distortionary or if $G^{1}=G^{2}$.

The difference $W^{*}-W^{A}$ is the gain from forming an integrated federation, coming from contingent revenue sharing and thus the smoothing of distortionary taxes across regions. This integrated economy represents a benchmark in two respects. First, there is only a single government so that any interaction between governments within a multi-region union is non-existent by assumption. Second, the government in this case has commitment power: it sets taxes prior to the actions of the agents.

We now study allocations within a multi-region economy in which these two aspects of the benchmark are relaxed. This will provide insights into the interaction in the fiscal policies of a central government and multiple regional governments.

As we shall see, the incentives which underlie revenue sharing in the integrated federation are also a source of the commitment problem. This highlights a central tension within a federation. Revenue sharing is welfare improving as it facilitates the smoothing of distortionary taxes. But, without commitment by the central government, regions will take advantage of the taxation power of the central government to the detriment of the other region.

\section{Decentralized allocations with Autonomous Regions}

Our interest is the allocation from an economy in which regional governments are autonomous and interact with the central government. In this setting, we can understand the conditions for bailout and the welfare properties of federations with and without commitment by the central government, using the integrated solution as a benchmark.

In this two-region union, taxation power is split across a hierarchy of government: the central government $(C G)$ and the government representing the agents in region $i(R G i)$ are the active fiscal players. The

\footnotetext{
${ }^{9}$ Specifically, (16) implies $c_{1}^{1}=c_{1}^{2}$ and, using (5), $c_{2}^{1}=c_{2}^{2}$.
} 
government in region $i$ will select tax rates $\tau_{t}^{i}$ for $t=1,2$ and the $C G$ will set a common tax rate, denoted $\tau^{C}$, on period 2 labor income. The regional governments can issue debt to cover the excess of regional expenses over regional tax revenues. Since our focus is on tax obligations for the financing of debt obligations, we do not consider a $C G$ tax in period 1 .

In addition to controlling different fiscal instruments, these three governments have different objectives. As above, the $C G$ maximizes the weighted sum of the utilities of agents across regions while the regional governments are interested only in the welfare of the agents within their region.

A key aspect of this multi-regional structure is the timing of decisions by these three governments. We consider the environment in which the $C G$ is unable to commit to its period 2 tax rate. The order of moves is:

\section{- Period 1}

- Nature selects $G^{1}, G^{2}$.

- Regional government $i$ sets $\tau_{1}^{i}$

- Private agents choose period 1 employment and saving

\section{- Period 2}

- Central government sets $\tau^{C}$ and distributes revenues to regions

- Regional government $i$ sets $\tau_{2}^{i}$. If it does not cover its obligations, agents incur a utility loss (default cost) of $\epsilon$

- Private agents choose employment for period 2

The lack of commitment by the $C G$ pertains to the choice of $\tau^{C}$ relative to period 1 taxes set by the regional governments. ${ }^{10} \mathrm{We}$ do allow the $C G$ to choose $\tau^{C}$ prior to the choice of the governments in period 2 and this allows the $C G$ to smooth taxes across regions. But, the $C G$ sets its tax rate given the period 1 taxes chosen by the regional governments. Thus a regional government anticipates a response by the $C G$ to variations in regional debt.

Using the results of the integrated economy, summarized in Proposition 2, as a benchmark, our goal is to understand when that allocation can be decentralized in the two-period game between governments outlined above. Our results indicate that only in special circumstances can the integrated solution be decentralized.

A key aspect for some of the results is the amount of debt issued by region $i$ held by residents of the other region. Let $\theta^{i}$ denote the fraction of region's $i^{\prime} s$ debt held by its own members, and $B^{i}$ the amount of period 1 debt issued by the region $i$ government per region $i$ agent.

Note that embedded in the extensive form game is a default cost of $\epsilon$, denominated in utility terms. This cost is intended to capture penalties associated with default, such as trade and borrowing restrictions.

\footnotetext{
${ }^{10}$ Our results are not dependent on the details of the timing of the game in period 2. This point is important as it indicates that the results do not rely on a form of commitment to the order of moves in the period 2 game.
} 


\subsection{A Ricardian Equilibrium}

We begin with a special case in which the integrated solution can be decentralized in the multi-region economy. The key to this result is the assumption that taxes are not distortionary: $\gamma \rightarrow \infty$, implying $n(\tau)=\eta$.

To construct this equilibrium, assume $\theta^{i}=1$ for $i=1,2$. In equilibrium, agents will be indifferent regarding the composition of their portfolio since government debt and storage will yield the same return. Yet, the distribution of debt holdings will matter for the equilibrium outcome. The assumption $\theta^{i}=1$ for $i=1,2$ is thus innocuous at the level of the individual but is instrumental in the construction of the equilibrium.

In this equilibrium, the period 2 debt obligations of region $i$ will be paid by tax revenues from region $i$ taxation. Agents in both regions will anticipate this taxation in deciding upon their savings in period 1.

Since each region holds its own debt, there are no links across the regions in equilibrium and thus a Ricardian outcome should occur as long as the $C G$ has no incentive to intervene. As we shall see, in the Ricardian equilibrium, the $C G$ has no incentive to intervene since the consumption levels of the agents are equal across the two regions.

Proposition 4 If the default cost is near zero, i.e. $\epsilon \rightarrow 0$, there exists a Ricardian equilibrium with nondistorting taxes iff $\theta^{i}=1$.

We call this a Ricardian equilibrium because consumption levels and thus welfare are independent of the level of $G^{i}$ and the timing of taxes needed to pay for the public good. In equilibrium each regional government pays off its own debt, and recognizes this responsibility when deciding on the tax rate in the first period. Consumption levels are smoothed over time and are equal across regions.

We compare this allocation to that obtained under autarky and the integrated federation. There is complete consumption smoothing across regions in all cases and no interaction across regions. Thus there are no gains from integration when taxes are not distortionary but, at least in the Ricardian equilibrium, no welfare costs either. Formally, letting $W^{R}$ be expected utility in the Ricardian equilibrium, we find

Proposition 5 When taxes are not distortionary, $\gamma \rightarrow \infty$, the Ricardian equilibrium is the same allocation as that obtained under autarky and integrated federation: $W^{R}=W^{A}=W^{*}$.

Though the $C G$ is not committed to $\tau^{C}=0$, ex post it has no incentive to bailout the regional governments. There is no incentive to bailout because: (i) period 2 consumption allocations are equal across regions and (ii) there is no gain to the smoothing of taxes since labor supply is totally inelastic. We now study how incentives for bail-out arise.

\subsection{Bail-out}

The construction of the Ricardian equilibrium rests on two assumptions. First, debt of region $i$ is held only by region $i$ agents. Second, the tax on labor income is not distortionary. Thus the only incentive 
for intervention by the $C G$ is to smooth consumption but, in equilibrium, there was no need for further consumption smoothing.

We now argue that if these assumptions are relaxed, then the $C G$ will have an incentive to bailout the regional governments in period 2. This bail-out will destroy the Ricardian equilibrium and lead to socially inefficient allocations: the resulting allocations will differ from the integrated solution.

The discussion is organized around two rationales for a $C G$ bail-out. ${ }^{11}$ The first concerns the gains from ex post consumption smoothing across regions when taxes are not distortionary. The second comes from the desire of the $C G$ to smooth distortionary taxes across regions even when there are no gains to consumption smoothing.

\subsubsection{Consumption Smoothing}

Under the assumption that taxes are not distortionary, we characterize a bail-out equilibrium driven by the desire of the $C G$ to smooth ex post consumption across regions in period 2. The CG's optimization problem of maximizing $\sum_{i} \Delta^{i} v\left(c_{2}^{i}\right)$, given available resources in period 2, results in equalization (smoothing) of consumption levels across regions due to the strict concavity of $v(\cdot)$.

We analyze the outcome in period 2 given the levels of debt issued by each region, $B^{i}$, and the fraction of this debt held in total by all agents in region $i, \theta^{i}$, for $i=1,2$. After solving for the period 2 outcome, we characterize the choice of period 1 taxes by the regional governments.

The following proposition states the conditions for bail-out in the case of $G^{1}>G^{2}$. This is without loss of generality since the only difference across regions is in the realized value of $G^{i}$.

Proposition 6 For $G^{1}>G^{2}$ and $\varepsilon \rightarrow 0$ : (i) the CG fully bails-out the obligation of both regional governments, and (ii) regional governments choose not to tax their citizens in either period, iff $\theta^{1}<\Delta^{1}$ and $\theta^{2}>\Delta^{2}$.

This result about a $C G$ bail-out is intuitive. If $G^{1}>G^{2}$, then $s^{1}>s^{2}$ so region 1 households will, without intervention, have higher consumption in period 2. The $C G$ will intervene and bailout if that action redistributes in favor of region 2. Such a redistribution requires $\theta^{1}<\Delta^{1}$ and $\theta^{2}>\Delta^{2}$. The fact that more equitable consumption is desired is an immediate consequence of $v^{\prime \prime}(\cdot)<0$.

There is a subtle and important point here. Total consumption in the second period is fixed, given endowments and storage decisions. So, the redistribution by the $C G$ increases the consumption of region 2 agents and reduces the consumption of region 1 agents relative to the default allocation. Thus the redistribution per se is not favorable to region 1 agents. Still, their consumption is higher under a bail-out than if they paid the entire tax bill. In effect, the region 1 agents are able to take advantage of the desires of the $C G$ to redistribute consumption away from them.

\footnotetext{
${ }^{11}$ We are grateful to Marco Bassetto for discussions which led to the enhanced development of this section relative to an earlier draft.
} 


\section{Figure 1}

This is illustrated in Figure 1 which indicates the consumption levels of the old agents in both regions under different allocations. This graph takes as given the savings decisions of the agents and thus total resources available for consumption are fixed, as indicated by the negatively sloped resource constraint. The allocation under a bail-out is labeled $B$, the allocation under default is labeled $D$ and the one under regional taxation is labeled $R$. As seen in this figure, the bail-out by the $C G$ redistributes from region 1 to region 2 agents relative to the default allocation. Still this allocation is preferred by region 1 to the one achievable with regional taxation.

There are other implications of the bail-out. First, the regional governments set taxes in period 2 equal to zero, given the bail-out by the $C G$. Further, the regional governments in period 1 will anticipate a bail-out by the government. Consequently each regional government will alter the pattern of intertemporal taxation by reducing the tax in period 1 to zero as well and thus use the $C G$ bail-out of its debt obligation to share the burden of taxation with the other region.

Letting $\tilde{W}$ be expected life-time utility in a bail-out equilibrium, we find

Proposition 7 The expected utility in a bail-out equilibrium is less than the expected utility under integration and autarky: $\tilde{W}<W^{A}=W^{*}$.

As indicated in Figure 1, the equilibrium allocation with bail-out is different from the Ricardian allocation. Since the Ricardian equilibrium entailed the same allocation of consumption as in the integrated solution, the equilibrium characterized in Proposition 6 yields lower expected utility than the integrated solution. Further, since the Ricardian equilibrium is the same outcome as autarky, expected utility under bail-out must be less than expected utility under autarky.

This bail-out result contrasts with the Ricardian equilibrium characterized in Proposition 4. Comparing these results, the key difference between bail-out and regional taxation is in the holding of the regional debt. In the construction of the Ricardian equilibrium, it was crucial that $\theta^{i}=1$ for $i=1,2$. Else, the regional government would choose to default. If the bulk of the debt is held by the region with the lower level of saving, then the $C G$ will have an incentive to bail-out the regional government and thus effect a more equitable distribution of consumption.

Comparing these proposition highlights an important element of the model without distortionary taxes: there are multiple equilibria. If we fix $G^{1}>G^{2}$, there will be an isolated Ricardian equilibrium in which $\theta^{i}=1$ for $i=1,2$ and a set of bail-out equilibria satisfying $\theta^{1}<\Delta^{1}$ and $\theta^{2}>\Delta^{2}$. For other values of $\theta^{i}$, there will be default and thus these are not equilibria. This multiplicity is reflected in the distribution of debt holdings across the economy: in the Ricardian equilibrium debt is held within the issuing region while debt holdings are more widespread in the bail-out equilibrium. Of course, at the individual level, agents remain indifferent about the composition of their portfolios. 


\subsubsection{Tax Smoothing}

Here we explore a second basis for a bail-out by the $C G$. If the amount of debt outstanding is not equal across regions, i.e. $B^{1} \neq B^{2}$, then a common tax will minimize the distortion associated with the repayment of the regional debt. Thus a bail-out will occur in equilibrium. ${ }^{12}$

To make this argument clear, we make two assumptions. First, assume labor taxes are distortionary as employment depends on the tax rate. Second, we assume $v^{\prime \prime}(\cdot)=0$ throughout this section so that the consumption smoothing motive is eliminated from the analysis. From the discussion of the integrated solution, $v^{\prime \prime}(\cdot)=0$ implies tax smoothing across time and across regions is optimal.

In the equilibrium we construct, there is full bail-out of regional obligations in period 2 so that $\tau_{2}^{i}=0$, for $i=1,2$. In anticipation of this bail-out, the regions run excessive deficits and this creates a socially inefficient distortion in the intertemporal pattern of labor taxes.

Proposition 8 Given $B^{i}, i=1,2$, there exists a bail-out equilibrium in which $\bar{\tau}_{2}^{i}=0, I(\bar{\tau})=R \sum_{i=1,2} \Delta^{i} B^{i}$ and the regional governments set period 1 tax rates lower than $\bar{\tau}$.

The second period outcome, given $B^{i}$, is for the $C G$ to bailout the regional debt. In response, the regional governments set $\bar{\tau}_{2}^{i}=0$ for $i=1,2 .{ }^{13}$ In addition, the regional governments will reduce period 1 tax rates to take advantage of the $C G$ bail-out in period 2. However, the tax rate in period 1 need not fall to zero since there is a utility loss to agents from having taxes excessively distorted across periods.

Turning to the issue of normative assessment of this bail-out equilibrium, we prove it is not always welfare reducing relative to the autarky equilibrium. In this discussion we assume that two regions are of the same size: $\Delta=\frac{1}{2}$. Letting $\bar{W}$ be the expected utility under bail-out for the tax smoothing case, we find

Proposition 9 The expected utility in a bail-out equilibrium is smaller than the expected utility under integration. If the correlation of the spending shocks is large (near 1), then a bail-out equilibrium is worse than autarky. The difference between the expected utility in a bail-out equilibrium and autarky increases with the variability of $G$ when the correlation of the spending shocks is sufficiently small (near -1).

Comparing the integrated and bail-out outcomes, there is smoothing of distortionary taxes across the regions in both cases. In the integrated solution, taxes were also smooth over time. For the equilibrium characterized in Proposition 8, in contrast, the anticipated bail-out of the central government induces the regional governments to run excessive deficits. As a consequence, distortionary taxes are not smoothed over time. This inefficiency is a consequence of the inability of the $C G$ to commit not to bailout the debt of the regional governments. Thus the equilibrium is not the same as that from the integrated economy and expected utility is lower than in the integrated solution.

\footnotetext{
${ }^{12} \mathrm{~A}$ sufficiently large $\varepsilon$ is needed to support this repayment. Else, the regional and central governments will all choose to default on outstanding debt.

${ }^{13}$ Here $\bar{\tau}_{t}^{i}$ is the tax rate of region $i$ in period $t$ and $\bar{\tau}$ is the period 2 tax rate set by the $C G$ in the bail-out equilibrium.
} 
The welfare cost of the bail-out equilibrium relative to autarky is that agents in one region are led to finance the excessive deficits of the other region. When the $\operatorname{corr}\left(G^{1}, G^{2}\right)$ is near 1 , the gains to tax smoothing across regions are small. In this case, the costs of the bail-out due to tax distortions are large enough that autarky yields expected utility in excess of expected utility under a bail-out.

Comparing the expected utility under bailout to autarky, there are two important factors highlighted in Proposition 9: the correlation and variability of the spending shocks. Relative to autarky, there are gains to tax smoothing across regions in the bail-out equilibrium. These gains are larger when the correlation of $G^{1}$ and $G^{2}$ is near -1 . Further, these gains are larger if the variability of $G$ is large.

Following the logic underlying Proposition 9, it is possible to construct parametric examples in which expected utility in a bail-out equilibrium exceeds that under autarky. To illustrate, suppose $\gamma=1, R=1$, $\Delta=\frac{1}{2}, G^{i}=\bar{G} \pm \varepsilon$ with equal probability, and $\operatorname{corr}\left(G^{1}, G^{2}\right)=-1$. We hold $\bar{G}$ constant, and compute the equilibria under the different regimes for different values of $\varepsilon$.

The construction of the bail-out equilibrium uses the first-order condition of a regional government, (26), along with the government budget constraint, (31), to solve for the two tax rates $\bar{\tau}^{1}$ and $\bar{\tau}^{2}$ given the fixed aggregate spending by the two regions, $\bar{G}$. Total regional government spending is constant due to the assumption that $\operatorname{corr}\left(G^{1}, G^{2}\right)=-1$. Likewise, tax rates in the integrated economy equilibrium are also independent of $\varepsilon$. In contrast, taxes in the autarkic equilibrium vary with $\varepsilon$.

For $\bar{G}=0.4$ there is a bailout equilibrium in which $\bar{\tau}^{1}=0.205, \bar{\tau}^{2}=0.3861$, and the tax rate for the integrated economy equilibrium is $\tau^{*}=0.2764$. Since there is no aggregate uncertainty, there is no variability in these equilibria. The outcome under autarky is constructed for each of the two possible realizations of $G^{i}$ using the budget constraint, (7), to compute the tax rate given $\varepsilon$. With $\varepsilon=0$, the expected lifetime utility under autarky exceeds that under bailout since there is no uncertainty in taxes under either regime but an intertemporal distortion in taxes under bailout. As the variability of $\tau^{A}$ increases with $\varepsilon$, the expected utility in autarky will decrease.

The welfare calculations are summarized in the Table 1 for three levels of uncertainty in taxes under autarky, represented by $\varepsilon$. The second column is the difference between expected utility in bailout and autarky, $\bar{W}-W^{A}$. If the variability of $G$, (and thus of $\tau^{A}$ ), is low enough, autarky dominates bail-out. But, as the variability of tax rates increases, the bail-out equilibrium generates higher expected utility than autarky.

\begin{tabular}{|c|c|}
\hline$\varepsilon$ & welfare gain to bailout, $\left(\bar{W}-W^{A}\right)$ \\
\hline 0.01 & -0.0189 \\
0.05 & -0.0115 \\
0.1 & 0.0463 \\
\hline
\end{tabular}

Table 1: Welfare Comparison: Autarky vs. Bailout

There is an interesting contrast between this result and that obtained for the welfare implications of 
monetary union with a centralized monetary authority. Proposition 3 of Cooper and Kempf (2004) argues that there are welfare gains to a monetary union when shocks are highly correlated across countries. The argument, following Mundell, is that the delegation of a policy instrument to a central authority is not too costly when shocks are sufficiently positively correlated. Yet, as indicated by Proposition 9, when shocks are highly correlated, then there are little gains to tax smoothing and autarky may dominate a weak federation. Thus, in contrast to monetary unions, federations created to take advantage of tax smoothing are more likely to be welfare improving if shocks are not too positively correlated.

\subsection{The Value of Commitment}

The conclusion from this analysis is that the combination of autonomous regional governments and a central government leads to equilibria which will generally differ from the integrated (first-best) equilibrium, except under very stringent conditions. This raises the question of the source of this sub-optimality: is it the plurality of fiscal players or the lack of commitment by the central government? We argue that the root of the problem is the weakness of the central government: the $C G$ sets taxes in the second period, given the choice of tax rates for period 1 by the regional governments. It is then merely responding to incentives put in place in the first period by the regional governments: that is, the $C G$ is "weak".

Suppose to the contrary that the $C G$ is "strong": it chooses period 2 fiscal and redistributive policy at the beginning of period 1 , before the regional governments set fiscal policies for periods 1 and 2 . It is now the regional governments which respond to the $C G$.

Here we consider a "reasonable" commitment policy consistent with fiscal federalism. Assume the $C G$ is able to credibly announce to the RGs and the agents in the whole economy both the central tax rate $\tau^{C}$ and the fraction of the $C G$ 's total fiscal income that each region will receive, i.e. the commitment to a revenue sharing scheme between regions. For this type of strategic stance and its transfers, we find:

Proposition 10 Under commitment of the central government, if there are no labor distortions or $v(\cdot)$ is linear, the unique equilibrium is the integrated allocation.

Even with multiple fiscal agents, the integrated allocation may be supported. Thus, the suboptimality of the equilibria with bail-out reflects the inability of the $C G$ to commit.

In these two cases, the commitment equilibrium, being equivalent to the integrated equilibrium, is also equivalent to the Ricardian equilibrium. This proposition makes clear that, despite an apparent reduction in fiscal tools (the central government only taxes in the second period to make transfers to indebted regional governments), the ability to commit restores the first-best allocation. By committing to interregional transfers (it taxes equally and redistributes across regions), the $C G$ is able to eliminate the free-riding of RGs.

This result makes clear that the lack of commitment is crucial for reaping the fiscal benefits of integration. A strong $C G$ is able to create a system of revenue sharing which facilitates the smoothing of distortionary 
taxes across regions. But, when a $C G$ is weak, its ability to smooth the burden of distortionary taxation becomes a tool for bail-out and the consequent effects on welfare.

\section{Fiscal constraints}

The analysis has shown the benefits of smoothing distortionary taxes across regions. These gains to fiscal integration are attainable if the central government can commit to its fiscal policy.

But, without commitment power, these gains may be offset by the choices of regional governments to lower taxes in the first period. This adverse incentive effect appears in the form of $\tau_{1}^{i}$ being too low and thus $B^{i}$ too high relative to the integrated allocation. As a consequence, the bail-out is ex ante welfare reducing and, as we have seen, may imply that autarky is preferable to joining the federation.

It is instructive to use the model to interpret how various federations have attempted to deal with this commitment problem though various forms of fiscal constraints. Our goal here is not to explain the differences across these federations but rather to study them through the lenses of our model.

\subsection{Argentina}

Argentina is one of the most decentralized federations and has struggled with bailouts at the federal level. The sub-national "provincial" governments are responsible for almost $50 \%$ of the total consolidated public expenditures (more than 2/3 when pensions are excluded). However, most taxation powers are delegated to the central government. Hence, Argentina is characterized by large vertical transfers; in 1997, 56\% of provincial expenditures were financed through transfers from the central government. Nine provinces finance less than $20 \%$ of their expenditures with their own resources.

The intergovernmental transfer scheme appears particularly complex, Saiegh and Tommasi (1999) call it the 'federal fiscal labyrinth' of Argentina. Altogether in the 90's, both the central and the provincial governments have run large deficits. As a result, the provincial debts soared, growing on average from $40 \%$ of total revenues in 1994 to $55 \%$ in 1999.

Provinces facing unsustainable deficits have regularly been bailed-out by the central government, through various schemes, as discussed in Tommasi, Saiegh, and Sanguinetti (2001). These bail-outs have represented a significant proportion of the financial needs of provinces: in 1994, they amounted to almost $90 \%$ of the total provincial deficits. In particular, the pension regimes of 11 provinces have been nationalized between 1994 and 1996.

Altogether the central government seems unable to monitor the provincial fiscal policies, both in terms of taxation and public expenditures. According to Nicolini, Posadas, Sanguinetti, Sanguinetti, and Tomassi (2002), this has created "a general moral hazard problem that undermines the incentives of lower units to behave in fiscally responsive ways".

From the perspective of our model the mixture of large intergovernmental transfers, low control of lo- 
cal public expenditures and recurrent bail-outs are clearly indicative of a weak central government, lacking commitment power, and a sub-optimal situation, characterized by large distortions due to the tax system. Various institutional reforms such as the currency board system put in place in the 1990s and the ensuing discussions of dollarization were attempts to reinforce the power of the central government to resist pressures from the provincial fiscal authorities. However these reforms have been incomplete as they were not addressing the core of the problem: the federal fiscal labyrinth that left the central government vulnerable to appeals for bailing out by regions with large debts. ${ }^{14}$ The task confronting Argentine public authorities is to directly tackle the issue of distorted fiscal federalism with the aim of stricter fiscal responsibilities for the provincial governments. A survey of the various plans aiming at modifying the intergovernmental fiscal relations in Argentina that have been discussed and enforced in the recent years (Cuevas (2003)) concludes that while useful they do not represent a major break from the past.

\subsection{U.S.}

The U.S. is a federation of a different nature than Argentina. Relative to Argentina, the central government in the U.S. is largely immune to fiscal pressures of the regional (state) governments.

There are automatic interregional transfers from the Federal budget to the states. For example, the Welfare Reform Act of 1996 replaced a system of federal transfers automatically linked to welfare expenditures decided by state authorities by a system of lump-sum federal transfers with the states being fully responsible for any additional dollar spent on welfare. This is a clear evidence of the inability of states to pressure the Federal government for more aid.

All states but one (Vermont) have a fiscal constraint on their ability to borrow. Their stringency is not uniform and they do not forbid creative accounting measures. As a consequence, the effectiveness of these constraints is disputed. Whereas Poterba (1996) found that they have been effective on limiting state fiscal profligacy, a recent study by Canova and Pappa (2004) claims that these effects have been overemphasized: the differences between states with restrictive limits and states with looser ones are statistically and often economically unimportant.

From our perspective, the federal transfer system can be characterized as an ex ante revenue sharing scheme, with a large commitment power given to the federal level. Excessive deficits at the state level financed by federal bailouts are unlikely in the U.S. federation. Hence, there is no wonder that the fiscal restraints on states' fiscal policies are found ineffective. If anything, one might argue that these limits are too severe in that state governments are unable to smooth taxes over time.

\subsection{E.U.}

The current fiscal situation and policies run in Europe have four main features. The EU does not qualify as a fiscal federation. The budget of the European commission is small and represent at most $1.30 \%$ of the

\footnotetext{
${ }^{14}$ Cooper and Kempf (2001) discuss these policies using a model of regional pressures within a federation.
} 
EU's GDP. For fiscal year 2005, the European commission proposes a budget representing 1.14\% of the EU's GDP. But the larger EU countries, including France and Germany pledge to limit it to $1 \%$ at most.

Moreover the European commission has hardly any autonomous source of income and depends partially on contributions made by member countries. In the constitutional treaty currently discussed, the devolution of taxing powers to the EU itself is possible but will request unanimous approval by the member countries: hence it remains an unlikely event at best. Finally its expenditures are earmarked for sectoral (agriculture) or structural (regional) policies. There is no scope for fiscal federalism in Europe. As far as the European Central Bank is concerned, a provision in the Maastricht Treaty explicitly prohibits any contribution from any of its entities to any public administration.

The regional governments use the fiscal tools at their disposal so as to stabilize the economy. According to Gali and Perotti (2003), discretionary public deficits have become more counter-cyclical in the EMU countries after the approval of the Maastricht Treaty creating the EMU than before. On the whole, public deficits in the euro zone have tended to decline on average in the 90's but have started to grow again after the actual launching of the euro in 1999.

Precisely for fear of an increase in national public deficits within the euro zone, which was perceived as a liability on the credibility of the European currency, EU countries set up the Stability and Growth Pact. The critical provisions of the pact were threefold: a) each country would have to balance its public deficit over the medium term, b) national annual public deficits (including all public administrations and agencies) would be limited to $3 \%$ of GDP, except under severely depressing conditions, c) in case of breach of this constraint, the faulty country would be liable to pecuniary penalties.

The model studied in Section 3 can easily be amended to accommodate restrictions on debt. In fact, it is straightforward to determine the set of debt restrictions which would reproduce the outcome under integration. The difficulty with considering these types of restrictions is commitment: in period 2 the central government may have an incentive to bailout the regional governments and thus relax these debt restrictions.

In fact, the restrictions in the Stability and Growth Pact have proven to be unenforceable. Following the November 2003 decision by the European council of Finance ministers not to apply these penalties to France and Germany despite their public deficits above 3\%, the European council issued a revision of the pact in March 2005. In effect, this version considerably weakens the fiscal discipline and its enforcement in the EU. The various limits set on national fiscal policies act more as guidelines than as effective constraints on the discretionary powers of national Treasuries.

From the perspective of our model, it is logical that, in the absence of fiscal federalism and any significant central fiscal authority in the EU, the national countries should be allowed to exert discretionary powers to stabilize their economies. But two inconsistencies appear in the EU situation. First, if there is no bail-out possibility because of the absence of any "federal" taxation, then there is no need to limit deficit spending. The importance of the Stability and Growth Pact as a way of curbing "excessive deficits" disappears when there is no central government that can be induced to make transfers to the national treasuries. National 
governments will have to face the subsequent consequences of their current deficits. Second, these limits on deficit spending by national governments, if enforced, are likely to be harmful as they limit tax smoothing. Therefore it is no surprise that lately the member countries have decided to loosen them.

Proposition 9 provides further insights into the EU. As argued in that proposition, federations can yield higher expected utility than autarky even if bail-outs occur in equilibrium. Thus, fiscal restrictions may not be necessary to have some welfare benefits from a federation. However, note that the EU, following the arguments of Mundell, was constructed with the idea that countries with positively correlated shocks were natural partners. While this may indeed be true from the perspective of a monetary union, Proposition 9 tells us that in this case the gains to fiscal integration may be relatively small since there is little room for tax smoothing across countries.

The absence of fiscal federalism in Europe is delicate to assess. According to our theory, a fiscal federalism scheme in Europe is desirable to smooth taxes across regions. But this requires a strong commitment technology such that the central/federal authority is not vulnerable to the bail-out of national authorities running deficits. From this perspective, rather than issuing unenforceable strict fiscal limitations or harmless guidelines, the European countries should rather think about the establishment of a credible fiscal federalism scheme.

\section{Conclusion}

The goal of this paper was to study the factors which determine who pays the obligation incurred by a region within a federation. Within our framework, the best policy is one of ex ante fiscal federalism. There are two advantages to such a policy. First, there are efficiency gains from spreading distortionary taxes across large groups of agents. Second, if the tax and transfer policy is determined prior to the setting of region specific taxes, then the outcome is time consistent: the central government has an incentive to maintain its promises and not to finance additional deficit spending.

But the central government may not have the commitment power needed to support this allocation. Ex post the central government may be induced to bailout the regional government in order to smooth consumption and distortionary taxes across the regions.

We characterize the conditions under which bailouts occur and their welfare implications. We associate the occurrence of bail-outs with the inability of the central government to commit. This does not imply that autarky is preferred to a "weak" fiscal federalism where bail-outs occur. Focusing on the tax smoothing motive, a weak central fiscal federalism scheme may be better than autarky when the correlation between regional public expenditures shocks is low and their variance is sufficiently large. But, when the shocks across regions are highly positively correlated, then the bail-outs dominate and there is a welfare loss from the federation relative to autarky. We discuss some observations on integovermental fiscal relations in the US, EU and Argentina, in light of these insights.

One important element in the interaction between regions and the central government missing from our 
analysis is monetary policy. In the case of Argentina, the creation of regional monetary instruments during the currency period, and more generally the monetization of regional debt, played a key role in the economic crisis of 2001. For the E.U., even though there is no federation income tax, there is a central monetary authority and thus pressure from individual countries may still be exerted upon that entity.

A second element for future consideration is the determination of the default costs. These are taken as given here and do play a role in supporting bail-out equilibria with tax-smoothing. The source of these costs and, more interestingly, how they are determined within a federation, are of interest. These matters remain for future study. 


\section{Appendix}

\section{Proof of Proposition 1}

Proof. The $R G i$ chooses $\left(\tau_{1}^{i}, \tau_{2}^{i}\right)$ to maximize $W\left(\tau_{1}^{i}, \tau_{2}^{i}\right)$ subject to the government budget constraint, $(7)$. Letting $\lambda$ be the multiplier on (7) and using (3) and (6), the first-order conditions for the choice of taxes by $R G i$ are

$$
u^{\prime}\left(c_{1}^{i}\right) n\left(\tau_{1}^{i}\right)=\lambda I^{\prime}\left(\tau_{1}^{i}\right)=\lambda n\left(\tau_{1}^{i}\right)\left(1+\xi\left(\tau_{1}^{i}\right)\right)
$$

and

$$
R \beta v^{\prime}\left(c_{2}^{i}\right) n\left(\tau_{2}^{i}\right)=\lambda I^{\prime}\left(\tau_{2}^{i}\right)=\lambda n\left(\tau_{2}^{i}\right)\left(1+\xi\left(\tau_{2}^{i}\right)\right) .
$$

Using (5), these two first order conditions imply $\xi\left(\tau_{1}^{i}\right)=\xi\left(\tau_{2}^{i}\right)$ and hence $\tau_{1}^{i}=\tau_{2}^{i} \equiv \tau^{i A}$.

Let $V\left(G^{i}\right) \equiv W\left(\tau^{A}\left(G^{i}\right), \tau^{A}\left(G^{i}\right)\right)$ where $\tau^{A}\left(G^{i}\right)$ is given in Proposition 1 along with the regional government's budget constraint of $G=I\left(\tau^{A}\right) \frac{(1+R)}{R}$. Taking a derivative of $V\left(G^{i}\right)$ with respect to $G^{i}$ and using (5) implies

$$
V^{\prime}\left(G^{i}\right)=u^{\prime}\left(c_{1}^{i}\right)\left(1-\frac{1}{1+\xi\left(\tau^{A}\left(G^{i}\right)\right.}\right) .
$$

As $\xi(\tau)=\frac{-\tau}{\gamma(1-\tau)}, \frac{1}{1+\xi}>1$ as long as $\tau \in\left(0, \frac{\gamma}{1+\gamma}\right)$. This restriction on $\tau$ is justified by observing that $\tau=\frac{\gamma}{1+\gamma}$ is the tax rate which maximizes the government tax revenue, $\tau n(\tau)$. As $\gamma>0, \xi\left(\tau^{A}\left(G^{i}\right)\right) \in(-1,0)$ and so $V^{\prime}\left(G^{i}\right)<0$.

In order for utility to fall as $G^{i}$ increases, the consumption levels in at least one period must fall. From (5), the consumption levels move together. Thus as $G^{i}$ increases, consumption falls in each period.

\section{Proof of Proposition 2}

Proof. Taking derivatives of (8) with respect to $\tau_{1}^{i}$ and $\tau_{2}^{i}$ implies

$$
\begin{aligned}
Z^{\prime}\left(\tau_{1}^{i}\right) u^{\prime}\left(c_{1}^{i}\right) & =-\lambda I^{\prime}\left(\tau_{1}^{i}\right) \\
\beta Z^{\prime}\left(\tau_{2}^{i}\right) v^{\prime}\left(c_{2}^{i}\right) & =-\frac{\lambda}{R} I^{\prime}\left(\tau_{2}^{i}\right)
\end{aligned}
$$

for $i=1,2$ where $\lambda$ is the multiplier associated with (9). Using the household's first order condition of $u^{\prime}\left(c_{1}^{i}\right)=\beta R v^{\prime}\left(c_{2}^{i}\right),(13)$ and (14) imply

$$
\frac{Z^{\prime}\left(\tau_{1}^{i}\right)}{I^{\prime}\left(\tau_{1}^{i}\right)}=\frac{Z^{\prime}\left(\tau_{2}^{i}\right)}{I^{\prime}\left(\tau_{2}^{i}\right)}
$$

By definition, $\frac{Z^{\prime}(\tau)}{I^{\prime}(\tau)}=\frac{-1}{1+\xi(\tau)}$ which is monotone in $\tau$. Thus $\tau_{t}^{i}=\tau^{i *}$ for $i=1,2$.

Across regions, the first-order conditions imply

$$
\frac{u^{\prime}\left(c_{1}^{1}\right) Z^{\prime}\left(\tau^{1 *}\right)}{I^{\prime}\left(\tau^{1 *}\right)}=\frac{u^{\prime}\left(c_{1}^{2}\right) Z^{\prime}\left(\tau^{2 *}\right)}{I^{\prime}\left(\tau^{2 *}\right)}
$$


for $i=1,2$. The marginal "cost-benefit" ratios of tax distortions, measured by the ratio of marginal utility loss to marginal tax revenue gain, are equalized across regions.

To see that both tax rates increase in $G^{i}$, suppose without loss of generality that $G^{1}$ increases. If $\tau^{* 2}$ is fixed, then in order for the government's budget constraint to hold $\tau^{* 1}$ will have to increase. From the second part of Proposition 1, $c_{1}^{1}$ will fall. Thus the left side of (16) will fall for region 1 relative to region 2 as $\frac{Z^{\prime}\left(\tau^{1 *}\right)}{I^{\prime}\left(\tau^{1 *}\right)}=\frac{1}{1+\xi\left(\tau^{1 *}\right)}$ is an increasing function of $\tau^{1 *}$. Consequently, this policy of holding $\tau^{* 2}$ constant will violate (16). In order for (16) to hold, the increase in $G^{1}$ must be met by an increase in $\tau^{* i}$ for $i=1,2$.

\section{Proof of Proposition 3}

Proof. (i) $W^{*}<W^{A}$ is not possible since autarky is feasible in the integrated setting, implying $W^{*} \geq W^{A}$.

(ii) From the proof of Proposition 2, the tax rates under the two institutional structures are different whenever $G^{1} \neq G^{2}$. If these tax differences are distortionary, i.e. $\gamma<\infty$, then $W^{*}>W^{A}$.

(iii) If the shocks are perfectly positively correlated so that $G^{1}=G^{2}$ in all states of nature, then the regions are identical and thus expected utility is the same under integration as autarky. From (16), if $G^{1}=G^{2}$, then by symmetry $\tau^{1 *}=\tau^{2 *}$. As a consequence, the budget constraint holds for each region. This is exactly the same level of taxation which would occur in autarky so that $W^{*}=W^{A}$.

If taxes are not distortionary, $\gamma \rightarrow \infty$, then $\frac{Z^{\prime}(\tau)}{I^{\prime}(\tau)}=-1$ so that, using (13) and (14), taxes and thus consumption allocations are the same across regions in the integrated solution. As a consequence, the budget constraint holds for each region. This is also true for the allocation under autarky so that $W^{*}=W^{A}$.

\section{Proof of Proposition 4}

Proof. First we show that if $\theta^{i}=1, \forall i=1,2$ then $R G i$ is indifferent between tax and default and thus will choose to tax given the negligible default cost. Then we argue that the $C G$ will set $\tau^{C}=0$.

For this discussion, let $b^{i j}$ be the amount of region $j^{\prime} s$ debt held by a region $i$ agent. Thus $b^{i} \equiv b^{i i}+b^{i j}=$ $\theta^{i} \frac{B^{i}}{\Delta^{i}}+\left(1-\theta^{j}\right) \frac{B^{j}}{\Delta^{i}}$.

To check the incentives of the $R G i$, suppose $C G$ sets $\tau^{C}=0$ and thus does not bail-out in period 2. What are $R G i$ 's options given the (anticipated) CG's policy? If it taxes, private agents in region $i$ have utility of $v\left(\eta+R\left(s^{i}-b^{i}\right)\right)$. If it defaults the consumption is the same since only region $i$ agents hold region $i$ debt. With the negligible default cost, the region will choose to raise taxes to pay-off its debt: $\tau_{2}^{i} \eta=R b^{i}$.

Anticipating this taxation and $\tau^{C}=0$, private agent's savings in period 1 will solve

$$
W\left(\tau_{1}^{i}, \tau_{2}^{i} \mid G^{i}\right)=\max _{s^{i}} u\left(e+G^{i}+Z\left(\tau_{1}^{i}\right)-s^{i}\right)+\beta v\left(Z\left(\tau_{2}^{i}\right)+s^{i} R\right)
$$

Using the condition that $Z(\tau)=(1-\tau) \eta$, the first order condition is $u^{\prime}\left(e+G^{i}+\left(1-\tau_{1}^{i}\right) \eta-s^{i}\right)=\beta R v^{\prime}((1-$ $\left.\tau_{2}^{i}\right) \eta+s^{i} R$ ). Using $\tau_{2}^{i} \eta=R b^{i}$ and $G^{i}-\tau_{2}^{i} \eta=b^{i}$, the first-order condition can be written as

$$
u^{\prime}\left(e+\eta-\left(s^{i}-b^{i}\right)\right)=\beta R v^{\prime}\left(\eta+\left(s^{i}-b^{i}\right) R\right) .
$$


Thus, the difference $\left(s^{i}-b^{i}\right)$ is the same for all regions regardless of the period 1 realization of $G^{i}$. This means that along the path of the Ricardian equilibrium, period 2 consumption is equal across agents in the two regions. That is, anticipating tax financed debt service in period 2, agents save the excess regional transfer they get in period 1 , so that $c_{2}^{1}=c_{2}^{2}$.

To check the incentives of the $C G$, note that by choosing a value of $\tau^{C}$, it can transfer consumption across regions to maximize its objective of

$$
\sum_{i} \Delta^{i} v\left(c_{2}^{i}\right)
$$

given a resource constraint of:

$$
\sum_{i} \Delta^{i} c_{2}^{i}=\eta+R \sum_{i} \Delta^{i}\left(s^{i}-b^{i}\right)
$$

Given that $v(\cdot)$ is strictly concave, the $C G$ would choose a consumption allocation with complete equality. But this is precisely the consumption allocation in the Ricardian equilibrium. Thus the $C G$ is unable to intervene to further smooth consumption and it will choose $\tau^{C}=0$.

For any $\theta^{i}<1$, the $R G_{i}$ prefers default over regional tax for $\epsilon$ near zero, even when it anticipates that $C G$ will set $\tau^{C}=0$. If the regional government taxes agents in its region, some of the revenue is used to pay off agents in the other region. If the regional government defaults, consumption of agents in its region will thus be higher. So, for a sufficiently small default cost, there is no Ricardian equilibrium if $\theta^{i}<1$.

\section{Proof of Proposition 5}

Proof. In the Ricardian equilibrium, $R G i$ chooses $\left(\tau_{1}^{i}, \tau_{2}^{i}\right)$ to maximize $W\left(\tau_{1}^{i}, \tau_{2}^{i} \mid G^{i}\right)$, defined in (17) after $G^{i}$ has been realized, with $\tau^{C}=0$ subject to the constraint of $G^{i}=\left(I\left(\tau_{1}^{i}\right)+\frac{I\left(\tau_{2}^{i}\right)}{R}\right)$.

This is exactly the same problem a regional government solves in autarky, as in Proposition 1 . As the first-order conditions are the same for the two problems, so will be the level of expected utility: $W^{R}=W^{A}$.

From Proposition $3, W^{*}=W^{A}$ when there are no tax distortions. Thus in the Ricardian equilibrium $W^{R}=W^{*}=W^{A}$.

\section{Proof of Proposition 6}

Proof. Moving first at the start of period 2, the $C G$ selects a common tax and the distribution of the tax revenue across regions, given the outstanding debt obligations of the two regions. Specifically, it solves:

$$
\max _{T^{1}, T^{2}} \sum \Delta^{i} v\left(\eta+R k^{i}+\left(\frac{\theta^{i}}{\Delta^{i}}\right) T^{i}+\left(\frac{1-\theta^{j}}{\Delta^{i}}\right) T^{j}-\left(T^{1}+T^{2}\right)\right)-\Delta^{i} \epsilon \Xi_{\left(\Delta^{i} B^{i} R-T^{i}\right)}
$$

where $T^{i} \in\left[0, \Delta^{i} B^{i} R\right]$ is the $C G$ 's total payment to holders of region $i^{\prime} s$ debt, $T^{1}+T^{2}$ is the common economy-wide tax (per agent) needed to finance such payments, and $\Xi_{(x)}=1$ if $x>0$ and zero otherwise. Full bail-out by the $C G$ is denoted by $T^{i}=\Delta^{i} B^{i} R$ for $i=1,2$. 
If the $C G$ chooses less than full bail-out for any region $i$, then $R G i$ will default on the debt. As shown in the proof of Proposition 2, the $R G i$ is indifferent between default and taxation when $\theta^{i}=1$. For $\theta^{i}<1$, $R G i$ will strictly prefer default for $\varepsilon$ near zero. Thus the only equilibrium if $\theta^{i} \neq 1$ is full bail-out.

Social welfare under a full bail-out can be written as:

$$
\sum \Delta^{i} v\left(\eta+R k^{i}+D_{i}^{i}+D_{j}^{i}\right)
$$

where $D_{i}^{i}=\left(\frac{\theta^{i}}{\Delta^{i}}-1\right) \Delta^{i} B^{i} R$ and $D_{j}^{i}=\left(\frac{1-\theta^{j}}{\Delta^{i}}-1\right) \Delta^{j} B^{j} R . D_{j}^{i}$ is the net transfer to an agent in region $i$ from bailing-out region $j^{\prime} s$ debt, and $D^{i}=\sum_{j} D_{j}^{i}$ is the net transfer to such an agent from a full bail-out of all regional debts. The $D_{j}^{i}$ variables are key as they measure the direction and the extent of the redistribution from each of the two assets. As total consumption must equal total resources, $\sum \Delta^{i} c_{2}^{i}=\sum \Delta^{i}\left(\eta+R k^{i}\right)$, we have $\sum_{i} \Delta^{i} D_{j}^{i}=0$ for $j=1,2$.

The $C G$ will prefer to bailout the regional governments iff $D^{2}>0>D^{1}$. In this case, the bail-out will redistribute resources away from region 1 and towards region 2. Such a redistribution in favor of region 2 will lead to a more equitable distribution of consumption given the assumption $G^{1}>G^{2}$ which implies $s^{1}>s^{2}$. Hence, $D^{2}>0>D^{1}$ implies that the repayment of the debt through a common tax will raise the consumption of region 2 agents relative to region 1 . Since this allocation is more equitable than the allocation under default, the $C G$ prefers it to the default allocation.

For this to be an equilibrium, the $C G$ must have an incentive to fully bail-out both region's debt. For this we need both $D_{1}^{1}<0$ and $D_{2}^{1}<0$, or else $C G$ would be better off not bailing out the region that results in a net transfer to agents of region 1 . These conditions on $D_{j}^{1}$ mean, respectively, $\theta^{1}<\Delta^{1}$ and $\theta^{2}>\Delta^{2}$, as in the proposition.

If $D^{1}>0>D^{2}$, then the $C G$ will not have an incentive to bailout the governments. In this case, a bailout would redistribute in favor of region 1 and that is not ex post desirable to the CG. Thus $D^{2}>0>D^{1}$ is necessary for a bail-out to occur.

In anticipation of a bail-out, the $R G i$ solves the following problem, recognizing the impact of its own debt on the tax to be set by the $C G$ :

$$
\max _{\tau_{1}^{i}} u\left(G^{i}+e+\eta\left(1-\tau_{1}^{i}\right)-s^{i}\right)+\beta v\left(\eta(1-\tau)+s^{i} R\right)
$$

s.t.:

$$
\begin{aligned}
B^{i} & =G^{i}-\tau_{i} \eta, \\
\tau & =\frac{R}{\eta} \sum \Delta^{i} B^{i}, \\
u^{\prime}\left(c_{1}^{i}\right) & =\beta R v^{\prime}\left(c_{2}^{i}\right) .
\end{aligned}
$$

The first constraint defines the debt issued by region $i$ given its period 1 tax and the realized $G^{i}$. The second reflects the tax rate set by the central government in period 2 in a full bail-out, which satisfies $\tau \eta=R\left(\Delta B^{1}+(1-\Delta) B^{2}\right)$. The third constraint reflects agents' optimal saving. 
The derivative of $R G i$ 's objective with respect to $\tau_{1}^{i}$, taking into account the constraints, is:

$$
-\eta u^{\prime}\left(c_{1}^{i}\right)+\beta v^{\prime}\left(c_{2}^{i}\right) \eta \Delta^{i} R
$$

which is equivalent to:

$$
-u^{\prime}\left(c_{1}^{i}\right)+\beta R v^{\prime}\left(c_{2}^{i}\right) \Delta^{i},
$$

This is always negative given the saving first-order condition of the representative agent. Hence $\tau_{1}^{i}=0$.

\section{Proof of Proposition 7}

Proof. Immediate from Proposition 3 and the fact that the bail out allocation differs from the integrated allocation.

\section{Proof of Proposition 8}

Proof. At the start of period 2, the debt levels (per regional agent) in each of the two regions are given as $\left(B^{1}, B^{2}\right)$ where $B^{i}=G^{i}-I\left(\tau_{1}^{i}\right)$. The $C G$ moves first and selects a common tax, $\bar{\tau}$, for period 2 and transfers revenues across regions. This tax generates revenue of $\bar{\tau}\left(\Delta n\left(\bar{\tau}+\tau_{2}^{1}\right)+(1-\Delta) n\left(\bar{\tau}+\tau_{2}^{2}\right)\right)$. The remainder of the region's debt obligation is financed by a region $i$ specific tax, $\tau_{2}^{i}$.

Suppose, contrary to the actual game, that at the start of period 2, the $C G$ selects both regional taxes. It solves

$$
\max _{\tau_{2}^{1}, \tau_{2}^{2}} \sum_{i}\left(\Delta^{i}\left[Z\left(\tau_{2}^{i}\right)+R s^{i}\right]\right.
$$

subject to:

$$
R\left(\sum_{i} \Delta^{i} B^{i}\right)=\sum_{i} \Delta^{i} I\left(\tau_{2}^{i}\right) .
$$

Here $B^{i}$ is the amount of debt per region-head issued by $R G i$. Hence, this corresponds to an amount of debt per federation-head equal to $\Delta^{i} B^{i}$.

With $\lambda$ as the multiplier on the budget constraint, the first-order conditions are:

$$
Z^{\prime}\left(\tau_{2}^{i}\right)=\lambda I^{\prime}\left(\tau_{2}^{i}\right) \quad i=1,2
$$

Following previous arguments, this implies that $\xi\left(\tau_{1}^{1}\right)=\xi\left(\tau_{1}^{2}\right)$ so that the CG would choose $\bar{\tau}_{1}^{1}=\bar{\tau}_{1}^{2}$.

Thus, given debt levels the $C G$ would like the regions to set equal tax rates in the second period. This can be achieved by the $C G$ if it sets the common period 2 tax rate, $\bar{\tau}$, high enough to finance the entire debt obligation of the regional governments and distributes the revenues to them as needed to finance their debt.

This tax rate solves $I(\bar{\tau})=R\left(\sum_{i} \Delta^{i} B^{i}\right)$. Denote the (smallest) value of $\bar{\tau}$ satisfying this requirement as $\sigma\left(B^{1}, B^{2}\right)$ where $\sigma_{i}\left(B^{1}, B^{2}\right)=\frac{\partial \sigma}{\partial B^{i}}=\frac{\Delta^{i} R}{I^{\prime}(\bar{\tau})}$.

Thus the regional government's know that the central government will have an incentive to fully finance the debt obligations of the regions. Given this response by the $C G$, in period 1 each regional government 
solves:

$$
\max _{\tau_{1}^{i}} u\left(G^{i}+e+Z\left(\tau_{1}^{i}\right)-s^{i}\right)+\beta\left(Z\left(\sigma\left(B^{1}, B^{2}\right)\right)+R s^{i}\right) .
$$

Using $B^{i}=G^{i}-I\left(\tau_{1}^{i}\right)$, the first order condition can be written as

$$
u^{\prime}\left(c_{1}^{i}\right) Z^{\prime}\left(\tau_{1}^{i}\right)=\beta Z^{\prime}(\bar{\tau}) \sigma_{i}\left(B^{1}, B^{2}\right) I^{\prime}\left(\tau_{1}^{i}\right) .
$$

Using $\sigma_{i}\left(B^{2}, B^{2}\right)$ from above and $u^{\prime}\left(c_{1}^{i}\right)=\beta R$, we can rewrite this as

$$
\frac{Z^{\prime}\left(\tau_{1}^{i}\right)}{I^{\prime}\left(\tau_{1}^{i}\right)}=\Delta^{i} \frac{Z^{\prime}(\bar{\tau})}{I^{\prime}(\bar{\tau})}>\frac{Z^{\prime}(\bar{\tau})}{I^{\prime}(\bar{\tau})} .
$$

The inequality arises from $\Delta^{i}<1$ and $Z^{\prime}(\cdot)<0$. Using the definitions of $Z(\tau)$ and $I(\tau)$, this condition can be rewritten as

$$
\frac{1}{1+\xi\left(\tau_{1}^{i}\right)}<\frac{1}{1+\xi(\bar{\tau})}
$$

implying $\bar{\tau}_{1}^{i}<\bar{\tau}$ for $i=1,2$.

\section{Proof of Proposition 9}

Throughout this proof, the following assumptions are maintained:

- $v^{\prime \prime}(\cdot)=0$

- Distorting labor taxes, $(\gamma<\infty)$

- A joint probability distribution of regional spending shocks, $\left(G^{1}, G^{2}\right)$, with identical marginal distributions for $G^{i}, i=1,2$.

Tax revenue from a tax rate $\tau$ is $I(\tau)=\tau n(\tau)$, where $n(\tau)=(1-\tau)^{1 / \gamma}$. We only consider tax rates such that $\tau \in\left[0, \frac{\gamma}{1+\gamma}\right]$. On this interval, $I(\cdot)$ is strictly increasing and strictly concave. ${ }^{15}$

Since $v(\cdot)$ is linear and $u(\cdot)$ is strictly concave, $c_{1}^{i}$ is a constant determined by the saving first order condition. Thus $c_{1}^{i}=c$ for any realization of the random public spending shocks, $\left(G^{1}, G^{2}\right)$ in all three allocations under consideration: autarky, integrated economy, and the bail-out equilibrium characterized in Proposition 8.

Expected life-time utility of an agent is thus given by:

$$
W=u(c)+\beta E\left\{\left(R s\left(\tau_{1}\right)+Z\left(\tau_{2}\right)\right)\right\}
$$

where first and second period taxes, and hence labor income and savings, may depend on the realization of $\left(G^{1}, G^{2}\right)$, and consequently. From the agents' first period budget constraint:

$$
s\left(\tau_{1}\right)=G+e+Z\left(\tau_{1}\right)-c,
$$

\footnotetext{
${ }^{15}$ This can be directly verified from the first and second derivatives of $I(\cdot)$ for $\tau \in\left[0, \frac{\gamma}{1+\gamma}\right]$.
} 
so that

$$
W=u(c)+\beta R E\left\{G+e+Z\left(\tau_{1}\right)+\frac{Z\left(\tau_{2}\right)}{R}-c\right\} .
$$

The determination of $\left(\tau_{1}, \tau_{2}\right)$ will depend on the institution.

Autarky From Proposition 1, for every realization of $G$, a common tax rate is set for both periods, $\tau_{1}=\tau_{2}=\tau^{A}(G)$, which satisfies:

$$
G=\left(1+\frac{1}{R}\right) I\left(\tau^{A}(G)\right)
$$

Expected utility under autarky is then:

$$
W^{A}=u(c)+\beta R\left[e-c+E\left\{G+\left(1+\frac{1}{R}\right) Z\left(\tau^{A}(G)\right)\right\}\right],
$$

where the expectation is taken with respect to the marginal distribution of $G$.

Integrated Economy From Proposition 2 and the discussion following it for the linear $v(\cdot)$ case, there is a single tax rate for any realized pair of regional spending shocks, applied in all regions in both periods, which satisfies:

$$
\sum_{i} \Delta^{i} G^{i}=\left(1+\frac{1}{R}\right) I\left(\tau^{*}\left(G^{1}, G^{2}\right)\right) .
$$

The corresponding expected lifetime utility for the integrated economy is therefore:

$$
W^{*}=u(c)+\beta R\left[e-c+E\left\{G+\left(1+\frac{1}{R}\right) Z\left(\tau^{*}\left(G^{1}, G^{2}\right)\right)\right\}\right] .
$$

Tax-smoothing Bail-out From Proposition 8 we have a first period tax set by the regional government, $\bar{\tau}_{1}^{i}$, and a common second period tax set by the CG, $\bar{\tau}_{2}$, which depend on the realizations of public spending shocks in both regions. These tax rates must satisfy the budget constraint

$$
\sum_{i} \Delta^{i}\left(G^{i}-I\left(\bar{\tau}_{1}^{i}\right)\right)=\frac{1}{R} I\left(\bar{\tau}_{2}\right)
$$

The expected utility is then given by:

$$
\bar{W}=u(c)+\beta R\left[e-c+E\left\{G+Z\left(\bar{\tau}_{1}^{i}\right)+\frac{1}{R} Z\left(\bar{\tau}_{2}\right)\right\}\right] .
$$

Welfare Comparison: integration versus bail-out $W^{*} \geq \bar{W}$ is clearly true since the equilibrium under bail-out was feasible in the integrated solution. Moreover, as in Proposition 8, the tax rates in the bail-out equilibrium are not the same as those obtained under integration. Thus in this case $W^{*}>\bar{W}$. 
Welfare Comparison: Bail-out versus Autarky We first argue that if the correlation between $G^{1}$ and $G^{2}$ is near 1 , then $\bar{W}<W^{A}$. Comparing the welfare measures under autarky and bail-out, we can write $\left(\bar{W}-W^{A}\right)=\left(\bar{W}-W^{*}\right)+\left(W^{*}-W^{A}\right)$. As argued above, $\left(\bar{W}-W^{*}\right)$ is negative. By Proposition 3, $\left(W^{*}-W^{A}\right)$ is positive due to the ability to share tax revenues and thus smooth regional taxes. However, when $\operatorname{corr}\left(G^{1}, G^{2}\right)=1$, there is no scope for tax smoothing over the regions. Therefore $W^{*}=W^{A}$ and $\bar{W}-W^{A}$ is consequently negative. By continuity, this is true for $\operatorname{corr}\left(G^{1}, G^{2}\right)$ sufficiently close to 1 .

We now argue that $\bar{W}-W^{A}$ is increased if the correlation between $G^{1}$ and $G^{2}$ is near -1 and the variance of $G$ is sufficiently large. For this argument, we also assume $\Delta=\frac{1}{2}$.

When $\operatorname{corr}\left(G^{1}, G^{2}\right)=-1$ and $\Delta=\frac{1}{2}$, the average of the $G^{i}$ is always equal to the $\bar{G} \equiv \frac{1}{2}\left(G^{1}+G^{2}\right)$. Using (26) and (31), $\bar{\tau}$ and the $\bar{\tau}^{i}$ are constant in the bail-out equilibria. Therefore $\bar{W}$ does not depend on the variance of public expenditures.

But, this is not the case under autarky, where a regional government must bear the risk of variability in $G$. From Proposition 1, the regional government will set a tax rate constant over the two periods which depends on the realized value of $G$. With this in mind, the lifetime utility of an agent in an autarkic allocation is

$$
W^{A}(\tau)=\max _{s} u\left(\frac{1+R}{R} I(\tau)+e+Z(\tau)-s\right)+\beta(Z(\tau)+s R)
$$

where we used the government budget constraint $G=\frac{1+R}{R} I(\tau)$. Thus, instead of thinking about the variability of $G$, we will focus instead on the variability of $\tau$.

Using $n(\tau)=(1-\tau)^{\frac{1}{\gamma}}$ and the definition of $Z(\tau)$ from $(3), W^{A}(\tau)$ is strictly concave. The first derivative of $W(\tau)$ with respect to $\tau$ is

$$
W^{A^{\prime}}(\tau)=-\frac{\tau}{\gamma}(1-\tau)^{\frac{1-\gamma}{\gamma}}
$$

and the second derivative is

$$
W^{A^{\prime \prime}}(\tau)=-\frac{(1-\tau)^{\frac{1-2 \gamma}{\gamma}}}{\gamma} \frac{\gamma-\tau}{\gamma} .
$$

Under the restriction that $\tau \in\left[0, \frac{\gamma}{1+\gamma}\right], \tau<\gamma$ so that $W^{\prime \prime}(\tau)<0$.

Consider the following specification for the tax rate: $\tau=\mu+\sigma \epsilon$ where $\epsilon$ is a random variable with mean zero and $\mu$ is the mean of the tax rate. A given realization of $\tau$ induces a realization of $G$ for this region through $G=\frac{1+R}{R} I(\tau)$. We parameterize the variability of $\tau$ by $\sigma$. The strict concavity of $W(\tau)$ implies that $W(\tau)$ decreases when $\sigma$ increases. Thus $\bar{W}-W^{A}$ increases as the variability of $G$ increases.

\section{Proof of Proposition 10}

Proof. We define commitment as the fiscal policy applied in period 2 by $C G$, but decided by $C G$ at the beginning of period 1 , even before the regional governments decide and implement their own fiscal policies. The realization of $G^{i}$ for $i=1,2$ are known by $C G$ when it chooses its tax.

\section{Commitment with no labor distortions}

Consider the special case where $\gamma \rightarrow \infty$ and $n_{t}^{i}=\eta, \forall i, t$. This implies $I^{\prime}(\tau)=\eta=-Z^{\prime}(\tau)$. 
The $C G$ decides $\tau^{C}$ and the two transfers $T^{1}$ and $T^{2}$ given to the RGs in period 2. The budget constraint for the regional government $i$ is:

$$
G^{i}=\tau_{1}^{i} \eta+R^{-1}\left[\tau_{2}^{i} \eta+T^{i}\right]
$$

The tax policy of $R G i$ solves:

$$
\max _{\tau_{1}^{i}, \tau_{2}^{i}} u\left(G^{i}+e+Z\left(\tau_{1}^{i}\right)-s^{i}\right)+\beta v\left(Z\left(\tau_{2}^{i}+\tau^{C}\right)+s^{i} R\right)
$$

subject to (36). The FOCs are:

$$
\begin{aligned}
u^{\prime}\left(c_{1}^{i}\right) & =\lambda^{i} \\
\beta R v^{\prime}\left(c_{2}^{i}\right) & =\lambda^{i}
\end{aligned}
$$

where $\lambda^{i}$ is the multiplier associated with the budget constraint of $R G i$.

The maximization problem of $C G$ is:

$$
\max _{\tau^{C}, T^{1}, T^{2}} \sum \Delta^{i}\left[u\left(G^{i}+e+Z\left(\tau_{1}^{i}\right)-s^{i}\right)+\beta v\left(Z\left(\tau_{2}^{i}+\tau^{C}\right)+s^{i} R\right)\right]
$$

s.t.

$$
\begin{aligned}
u^{\prime}\left(c_{1}^{i}\right) & =\beta R v^{\prime}\left(c_{2}^{i}\right), \forall i . \\
T^{1}+T^{2} & =\tau^{C} \eta .
\end{aligned}
$$

When $\tau^{C}=0=T^{1}=T^{2}$, each $R G i$ acts in isolation and we obtain the Ricardian solution. Since, using Proposition 3, this is the same allocation as the integrated solution, the policy of $\tau^{C}=0=T^{1}=T^{2}$ is the solution to (39).

\section{Commitment with $v(\cdot)$ linear}

Define by $\Omega$ the per-capita tax income of $C G$

$$
\Omega=\tau^{C} \sum \Delta^{i} n\left(\tau^{C}+\tau_{2}^{i}\right)
$$

$\Omega$ is divided between the two regions according to:

$$
\Omega=T^{1}+T^{2}=\zeta^{1} \Omega+\zeta^{2} \Omega
$$

where $\zeta^{i}$ is the share of the tax receipts transferred to region $i$, and $\zeta^{1}+\zeta^{2}=1$. So, the per capita transfer received by the regional government in region $i$ is equal to $\Omega \frac{\zeta^{i}}{\Delta^{i}}$.

A commitment policy is a pair $\left(\tau^{C}, \zeta^{1}\right)$, chosen by $C G$ at the beginning of period 1 and applied in period 2 , which solves the optimization problem of $C G$. We prove that in the case of $v(\cdot)$ linear, the commitment solution is $\left(\tau^{*}, \Delta^{1}\right)$ and generates the same allocation as the integrated solution. 
Given a pair $\left(\tau^{C}, \zeta^{1}\right)$, the budget constraints for $R G i$ is:

$$
G^{i}=\tau_{1}^{i} n\left(\tau_{1}^{i}\right)+R^{-1}\left[\tau_{2}^{i} n\left(\tau_{2}^{i}+\tau^{C}\right)+\Omega \frac{\zeta^{i}}{\Delta^{i}}\right]
$$

The optimization problem of $R G i$ is

$$
\begin{gathered}
\max _{\tau_{1}^{i}, \tau_{2}^{i}} u\left(G^{i}+e+Z\left(\tau_{1}^{i}\right)-s^{i}\right)+\beta\left(Z\left(\tau_{2}^{i}+\tau^{C}\right)+s^{i} R\right) \\
\text { s.t. }(40), u^{\prime}\left(c_{1}^{i}\right)=\beta R .
\end{gathered}
$$

The FOCs are:

$$
\begin{aligned}
\beta R Z^{\prime}\left(\tau_{1}^{i}\right) & =\lambda^{i}\left[n\left(\tau_{1}^{i}\right)+\tau_{1}^{i} n^{\prime}\left(\tau_{1}^{i}\right)\right] \\
\beta Z^{\prime}\left(\tau_{2}^{i}+\tau^{C}\right) & =\frac{\lambda^{i}}{R}\left[n\left(\tau_{2}^{i}+\tau^{C}\right)+\left(\tau_{2}^{i}+\zeta^{i} \tau^{C}\right) n^{\prime}\left(\tau_{2}^{i}+\tau^{C}\right)\right]
\end{aligned}
$$

where $\lambda^{i}$ is the multiplier associated with the budget constraint of $R G i$, and using the definition of $\Omega$ in deriving (42).

The maximization problem of $C G$ is

$$
\max _{\tau^{C}, \zeta^{1}, \zeta^{2}} \sum \Delta^{i}\left[u\left(G^{i}+e+Z\left(\tau_{1}^{i}\right)-s^{i}\right)+\beta\left(Z\left(\tau_{2}^{i}+\tau^{C}\right)+s^{i} R\right)\right]
$$

s.t. (41), (42) and

$$
\begin{aligned}
\sum \Delta^{i} G^{i} & =\sum \Delta^{i}\left[\tau_{1}^{i} n\left(\tau_{1}^{i}\right)+R^{-1} \tau_{2}^{i} n\left(\tau_{2}^{i}+\tau^{C}\right)\right]+R^{-1} \Omega \\
\sum \zeta^{i} & =1 .
\end{aligned}
$$

The solution $\zeta^{i}=\Delta^{i}, i=1,2, \tau^{C}=\tau^{*}=\tau_{1}^{1}=\tau_{1}^{2}, \tau_{2}^{1}=\tau_{2}^{2}=0$ satisfies all the constraints and is identical to the integration solution, which is the first-best solution in the case of $v$ linear. Hence this is the solution to (6). 


\section{References}

Canova, F., and E. Pappa (2004): "Does it Cost to be Virtuous? The Macroeconomics Effect of Fiscal Constraints," CEPR discussion paper \# 4747.

Chari, V. V., and P. Kehoe (1998): "On the Need for Fiscal Constraints in a Monetary Union," Federal Reserve Bank of Minneapolis, Working Paper \#589.

Cooper, R., AND H. KempF (2001): "Dollarization and the conquest of hyperinflation in divided societies," Federal Reserve Bank of Minneapolis Quarterly Review, 25(3).

(2004): "Overturning Mundell: Fiscal Policy in a Monetary Union," Review of Economic Studies, $71(2)$.

Cuevas, A. (2003): "Reforming Intergovernmental Fiscal Relations in Argentina," International Monetary Fund wp \# 03/90.

Gali, J., and R. Perotti (2003): "Fiscal Policy and Monetary Integration in Europe," Economic Policy, $18,533-572$.

Nicolini, J., J. Posadas, J. Sanguinetti, P. Sanguinetti, and M. Tomassi (2002): "Decentralization, fiscal discipline in Sub-national governments and the bailout problem: The case of Argentina," InterAmerican Development Bank Research Network Working Paper, R-467.

Poterba, J. (1996): "Budget Institutions and Fiscal Policy in the US States," American Economic Review Papers and Proceedings, 86, 395-400.

Saiegh, S., And M. Tommasi (1999): "Why is Argentina's Fiscal Federalism so Inefficient? Entering the Labyrinth," Journal of Applied Economics, 2, 169-209.

Sanguinetti, P., and M. Tommasi (2004): "Intergovernmental Transfers and Fiscal Behavior insurance vs Aggregate Discipline," Journal of International Economics, 62, 149-70.

Tommasi, M., S. Saiegh, and P. Sanguinetti (2001): "Fiscal Federalism in Argentina," Economia, 2, 169-209.

Zarazaga, C. (1995): "Hyperinflations and Moral Hazard in the Appropriation of Seignorage," Federal Reserve Bank of Dallas, Working Paper 95-17. 


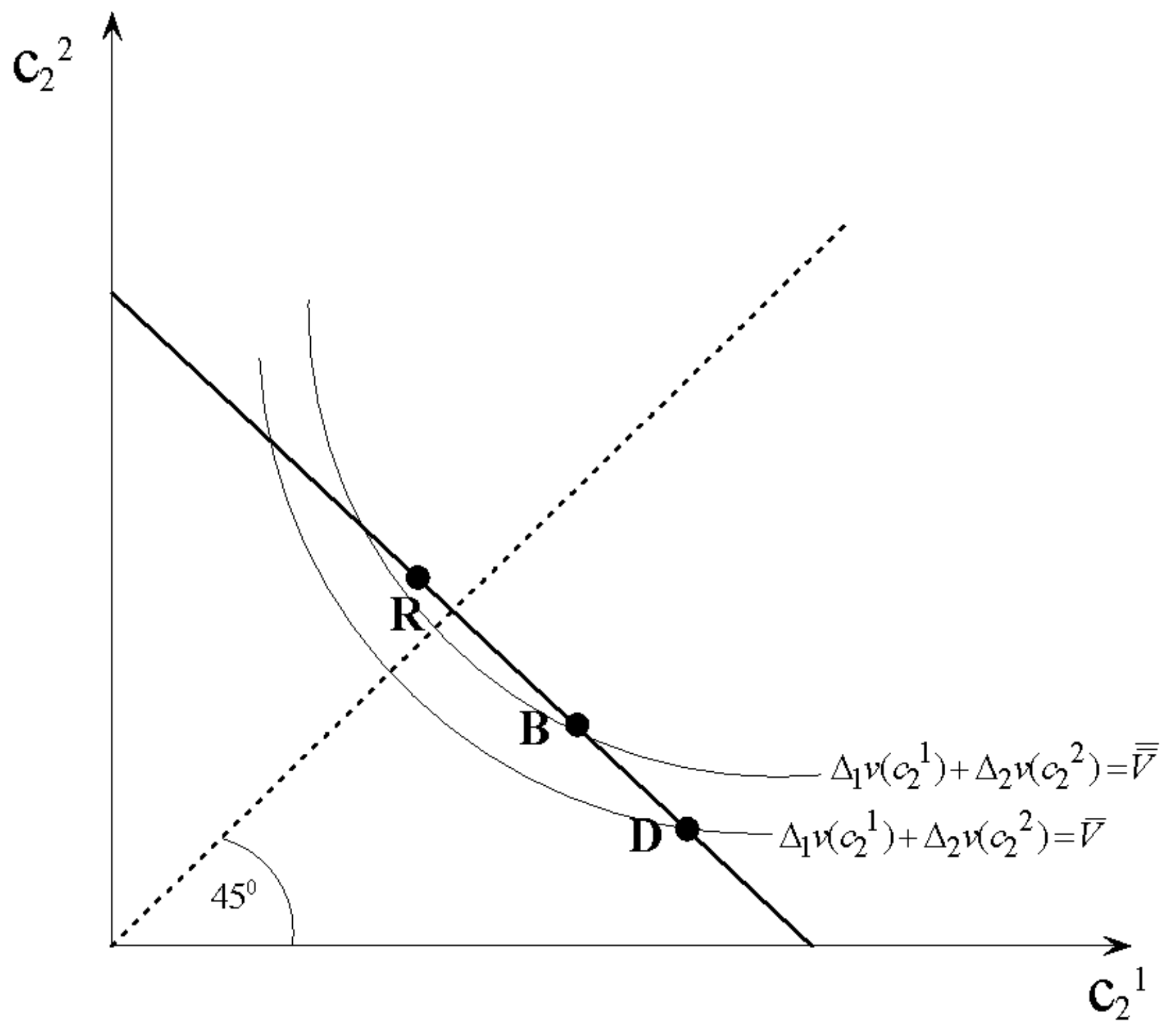

Figure 1: Bail-out equilibrium consumption across regions 